\title{
有关建筑工程给排水施工技术的应用
}

\author{
习目涁 \\ 山东润为建筑工程有限公司, 山东淮坊 261041
}

[摘要]从建筑工程的现状来看, 给排水施工的受关注程度是非常高的, 在展开给排水施工时, 如果其中的一个环节出现问题 的话，工程整体质量就会受到影响。所以说，展开给排水施工时，相关人员必须要了解施工的实际情况，同时要将环境检查、 勘测等方面的工作切实做到位，在此基础上将施工方案予以明确，如此方可使得给排水施工有序展开，并保证工程质量能够 达到标准要求。文章针对给排水工程技术的实际应用展开深入探析, 以期使得工程施工质量大幅提升。 [关键词]建筑工程; 给排水; 施工技术; 应用

DOI：10.33142/ec.v3i7.2320 中图分类号：TU82 文献标识码：A

\section{Application of Water Supply and Drainage Construction Technology in Construction Engineering}

DIAO Mubin

Shandong Runwei Construction Engineering Co., Ltd., Weifang, Shandong, 261041, China

\begin{abstract}
From the current situation of construction engineering, the attention degree of water supply and drainage construction is very high, if there is a problem in one of the links, the overall quality of the project will be affected. Therefore, during the water supply and drainage construction, the relevant personnel must understand the actual situation of the construction, at the same time, the environmental inspection, survey and other aspects of the work should be done in place. On this basis, the construction scheme will be clear, so that the water supply and drainage construction can be carried out orderly, and the project quality can meet the standard requirements. In this paper, the practical application of water supply and drainage engineering technology is analyzed in order to improve the construction quality.
\end{abstract}

Keywords: construction engineering; water supply and drainage; construction technology; application

\section{引言}

在当前时期, 国内经济发展速度持续加快, 城市规模也逐渐扩大, 这就为建筑工程的发展奠定坚实的基础。从建 筑施工的现状来看, 给排水管道的使用呈现出多样性, 尤其是塑料管道的应用范围逐渐扩大, 所以说, 为了保证安装 效果更为理想, 应该要依据实际需要选用合适的施工技术, 并保证技术应用更为灵活, 如此方可使得人们的生活所需 得到满足。

\section{1 建筑给排水工程的重要性}

(1) 社会经济持续发展使得广大人民群众的物质生活水平大幅提升, 对建筑质量也提出了更高的要求, 在展开建 筑工程施工时, 必须要对排水系统予以重点关注, 切实做好此方面施工方可保证建筑完整性, 大家的使用需求也能够 得到满足。展开施工时, 必须要对给排水施工予以重点关注, 通过有效措施来保证施工有序展开, 发生质量问题的几 率能够控制在最小范围内。

（2）建筑给排水施工呈现出明显的复杂性, 涉及范围相对较大, 而且在施工中必须要使用最为合适的技术。展开 施工时必须要合理控制施工技术, 保证施工质量能够达到标准要求, 如此方可使得建筑给排水系统的作用充分发挥出 来, 众所周知, 建筑给排水系统对广大居民的用水会产生直接影响, 而要保证施工用水能够得到满足, 则要保证给排 水施工有序展开, 确保施工质量达到标准要求, 方可使得建筑物完整性大幅提升, 广大群众的生活需求才能得到切实 保证。

\section{2 建筑工程给排水施工技术要点}

\section{1 建筑给排水施工的前期准备}

为了保证建筑给排水工程的施工能够有序展开, 必须要将相关的准备工作做到位, 完成好进度计划, 所需材料运 
抵施工场地, 并将采用的技术予以确定。技术人员要完成好技术交底工作, 同时要确保施工预案能够提前制定好, 相 关人员要对设计方案有切实的了解, 依据设备性能等来优化方案。在正式施工前, 要将施工进度予以明确, 人员分工 也要保证是合理的。对进度计划予以确定时, 必须要保证组织性、严密性切实提高, 并要将施工责任制构建起来, 在 此基础上完成好施工监管工作, 如此方可使得施工效率大幅提升。在对给排水管材进行选购时, 要将设计方案作为依 据, 管材运抵施工场地后, 指定专门人员展开检查, 确保各项参数和既定的标准相吻合, 而且要对合格证书、检测报 告等进行检查, 如果不达要求的话, 应该在第一时间清理出施工场地。

\section{2 给水管道安装技术要点}

墙体、楼板的管道安装是不可忽视的, 在固定管路时应该选用固定管卡, 确保上下、水平方向能够准确对应起来, 同时要做好防潮、防腐、防燃处理, 用于覆盖的板材应该是最为合适的。对管道进行连接时, 采用的方式包括法兰、 螺纹、热熔等。选用螺纹连接方式的话, 必须要细致检查板牙, 确保是完好的, 进行安装的过程中, 绞板后部的三角 爪应该确保中心位于同一点, 在予以加工时要确保管子两端能够保持平整状态, 切削量也要控制到位, 保证歪虎、烂 牙之类的问题能够切实消除。螺纹的松紧程度应该进行控制, 螺纹必须要保证一次性拧紧, 而且螺尾外露的部分应该 达到要求。如果选用法兰连接方式的话, 正式安装前应该要将铁锈、灰尘、油污等全部清除干净, 密封线也要予以剔 除, 之后将螺栓拧紧, 垫片不能出现位置偏移的情况。采用热熔、电热熔方式对管道进行连接的话, 热熔机具必须要 满足实际需要, 对管材进行切割时, 切口应该要平滑。焊接部位要彻底清洁, 加热头应该要和管材匹配, 在接通电源 后要对加热头温度予以关注, 温度最为合适时对管材管件进行加热处理, 进而完成连接工作。完成连接后应该要保证 冷却时间是足够的, 在此之后方可继续进行安装。全部安全工作结束后要走好压力试验工作, 保证不存在渗漏处。

\section{3 排水管道施工技术要点}

排水管的功能是确保生活污水能够顺利排出, 一般选用的是 PVC 管。在对接口进行粘结时, 要确保接口能够得到 有效处理, 使用的粘胶剂应该是最为适合的。当粘胶剂的涂抹完成后, 必须要立刻将管子插入到承插口中, 同时予以 定位处理。对排水管进行安装时, 坐标、标高、垂直度、弯曲度等均会出现误差, 此时必须要进行适当控制, 确保不 会超出既定范围。若想保证排水管不会发生堵塞的情况，应该要确保选用的配件是合适的，管道坡度也应该达到要求。

一般来说, 在对立管进行安装时, 乙字管的应用是较为普遍的, 因而要留好检修口, 如此可以保证将来的检修工作更 为简便。安装过程中, 立管、埋地排出管不可连接, 应该要选用托板基之类的方法, 立管预留的洞口也要进行封堵处 理, 当立管已经固定后方可将临时支撑物进行拆除。

\section{4 室内管道布置}

在对室内管道进行布置的过程中, 气体管道必须要位于液体管道之上, 热力管道位于冷水管道之上, 保温管道位 于常温管道之上, 金属管道位于非金属管道之上。展开并列安装时, 应该要保证管道间距是最为合理的。完成安装工 作后应该及时完成测试工作，保证安全性不受影响。

\section{3 建筑工程给排水施工技术的应用}

\section{1 生活给水系统}

生活给水系统由以下几个部分组成, 即洗刷用水、绿化用水、饮用水等, 而且在水质方面提出了很高的要求, 必 须要达到既定的标准要求。对生活用水进行分析可知, 冷水、饮水是两种常见的形式, 所谓冷水, 即是清洁程度较高 的生活用水; 所谓饮水, 指向的是可以直接饮用的水源, 通常来说, 高级住宅、宾馆中通常安装了此种管道。此类水 源必须要予以深度处理, 消毒工作必须要切实做到位, 这样方可保证饮用水的安全。当然, 饮用水拥有的品质是非常 高的, 所要投入的成本也是较大的。所以说, 在对给排水管道进行安装的过程中, 供水管道的设置应该要分开, 确保 各自独立，这样方可使得投入的成本控制在最小范围内，资源利用率也能够有大幅提升。

\section{2 辅助给水系统}

建筑用水设备的数量是较多的, 部分设备必须要相对独立, 和生活给水、消防给水等系统是存在一定差异的。辅 助给水系统主要包括下面几种, 一是循环冷却水系统, 在高层建筑中, 制冷设备所需的冷却水是非常多的, 为了使得 
用水能够切实减少, 要利用冷却塔来对水温予以降低处理, 进而予以循环使用。二是软化水系统, 锅炉房、热水系统 的用水必须要确保硬度是相对较低的, 如果冷水的水质达不到标准, 则要通过软化水系统进行处理。另外来说, 生活 用水、饮用水等同样要对其予以软化处理。三是游泳池循环水处理系统, 池水除了会受到污染外, 同时存在蒸发、散 热等情况, 因而在对池水进行处理时, 过滤、消毒是必须要做到位的, 而且要对散失热量予以适当补充, 系统设置应 该要相对独立。四是水景给水系统, 主要是利用的是天然水源, 而且用水量并不大, 所以可以通过循环方式供水。五 是复用水系统, 部分冷却水在使用之后, 水质并未出现明显的改变, 切实做好收集工作就能够在其他地方使用, 并不 需要重新进行处理。其和中水系统是存在很大区别的, 水质并不需要进行处理, 只要能够保证收集、输送更为顺畅即 可。六是中水系统，即是将建筑物排水当作是原水，对水质进行有效处理之后就能够作为杂用水使用。

\section{结语}

由上可知, 建筑给排水系统呈现出明显的复杂性, 在展开施工时, 采用的施工技术会对质量产生决定作用, 广大 居民的生活也会受到影响, 将施工技术得到充分应用时, 排水管道系统的运行才能保持正常状态。施工的过程中, 相 关人员应该要认识到给排水工程的重要性, 针对施工过程展开有效管控, 参与施工的人员必须要具有较高的专业素养, 并要依据实际需要选择合适的施工技术，如此方可使得施工的整体质量有大幅提升。

\section{[参考文献]}

[1] 熊文涛.建筑给排水工程施工技术的实践应用 [J].门窗,2019(21): 113 .

[2]赵子龙,刘川川.浅谈建筑给排水工程关键施工技术的应用 [J]. 建材与装饰, 2017 (32): 9-10.

[3]石艳国. 现代建筑工程中给排水施工技术及其应用探讨 [J].四川水泥, 2016 (09) : 198 .

[4]谭海源. 现代建筑给排水工程施工技术及其应用 [J]. 科技风, 2010 (04) : 140-150.

作者简介: 习目涁 (1986-), 男, 山东菏泽人, 汉族, 大学本科学历, 助理工程师, 研究方向为建筑工程施工技术。 